\title{
A hybrid approach based on ANP, ELECTRE and SIMANP metaheuristic method for outsourcing manufacturing procedures according to supply chain risks - Case study: A medical equipment manufacturer company in Iran
}

\author{
Hiwa Farughi* and Sobhan Mostafayi
}

Department of Industrial Engineering, Engineering College, University of Kurdistan, Sanandaj, Iran

\begin{tabular}{l}
\hline C H R O N I C L E \\
\hline Article history: \\
Received February 25, 2016 \\
Received in revised format: \\
March 28, 2016 \\
Accepted June 26, 2016 \\
Available online \\
June 262016 \\
\hline Keywords: \\
Supply chain risks \\
Combined multi criteria decision \\
making \\
ANP \\
ELECTRE \\
manufacturing process \\
SIMANP metaheuristic algorithm
\end{tabular}

\section{Introduction}

Since 1980, many of organizations have referred their manufacturing operations out of their internal borders in order to reduce manufacturing costs and thus reduce the cost of the entire system (Schoenherr et al., 2008). In fact, Outsourcing is an increasingly significant topic pursued via corporations seeking enhanced efficiency (Azadi \& Saen, 2011). Since parts and materials purchased from suppliers are accounted for a large part of production costs, therefore, supply chain cost management is as a key element in the management of total cost of the organization and increase profitability. In many countries, including China and India in 1980 and 1990, the production lines were transferred to South American countries such as Mexico (Schoenherr et al., 2008). These benefits include a significant 
reduction in production costs, cheap labor etc. However it can lead to a very complex supply network that creates a lot of risks. These risks include low quality products, increased transport costs, reduced reliability, disruption of supply chain, logistics problems, natural disasters and increased communication problems. Also nowadays, the fierce competition in global markets, the emergence of products with short life cycles and increasing customer expectations, have made commercial organizations to capitalize on their supply chain and its management. In addition, factors such as political issues, fluctuations in demand, technological change, financial instability and natural disasters increase uncertainty and risk in the supply chain which cause the formation of supply chain risk management (Vanany et al., 2009; Brindley, 2004). Risk management in the supply chain is through coordination and cooperation among the components of the supply chain in a way that ensures profitability and continuity of the supply chain (Tang, 2006).

The fact that these risks must be identified and examined initially by the organizations is very necessary and organizations must do efforts required to reduce the risks and increase the benefits of relocating any operations outside the internal borders in order to evaluate their outside alternatives for outsourcing some parts of manufacturing process and select the best ones. Since choosing a suitable outside alternative to do a part of manufacturing process is considered as a solution and an operational strategy among the other available solutions, being aware of the importance of making decisions about producing or buying from outside the borders is of the utmost importance. This is due to limited resources and lack of technology required in the production process. Nowadays supply chain risks are considered as an important criterion in supply chain management and since this paper seeks to evaluate and select the best solution among existing strategies related to manufacturing or purchasing from outside the organization, first the risks involved in the supply chain will be explained and then it is utilized to select the best alternative among existing ones in the following two-step process which is considered as the suggested method in this paper.

1. Identify existing risks in the supply chain by doing field survey in a medical equipment manufacturer company.

2. Combining ANP with ELECTRE method to remove less attractive alternatives and choose the best alternative from the ones available.

Finally, the SIMANP metaheuristic is developed method in order to provide a faster way to do the calculations with desired accuracy and the comparison of the results obtained is done through the AHPELECTRE proposed method.

The most important research questions include:

1. Which risks should be considered in the field of outsourcing decisions in the supply chain process?

2. What is an appropriate decision making structure to choose the best solution to transfer some parts of the production process outside the organization?

\section{Literature review}

\section{Supply chain management}

Supply chain management is a combination of art and science that improves ways of finding raw materials required for the production or service. Five main components of supply chain management include: 
$\checkmark$ Plan: plan is the strategic part of supply chain management.

$\checkmark$ Source: Selecting suppliers that will deliver the goods and services needed for a product or service.

$\checkmark$ Production: activities needed for the production, testing, packaging and finally preparation for delivery are done in this step.

$\checkmark$ Delivery: This part is also known as logistics. Coordination of receiving customer orders, develop a network of warehouses and set up a system to pay bills, make up this section.

$\checkmark$ Return: The problematic part of the supply chain. Building a network for receiving defective and returned products from customers and supporting customers who had problems with delivered product (Chopra, Sodhi, 2004).

\subsection{Risk}

Risk is an undesirable uncertainty, because it cannot be eliminated. So organizations are willing to tolerate that in return of getting some money. However they prefer to pay money to get rid of that. Also, organizations face with different risks in supply chain management (K.L.J.Litov, B.Yeung 2005). The following is a brief mention of the risks involved in the supply chain.

\subsection{Risks of supply chain}

Supply chain risks include cases that cause disruption and cut off the smooth flow of materials and information throughout the chain. This may include accidents related to transport operations, fires in warehouses, raw material shortages, low quality products, lack of efficiency and lack of trained personnel, flaws in the information system, etc. (Handfield, 2007). Risks involved in the supply chain can be divided into two general categories, internal risks and external risks. In practice, the internal risks and external ones in supply chain are not necessarily separated. As an example, it is possible that a financial problem in the organization is derived from the external environment caused by nonpayment of financial statements by the purchaser. But after a while it will become an important issue of liquidity for corporate executives refer to as internal risk. There may be other such cases (Waters, 2007). Internal supply chain risks stems from operating activities within the organization, including various events, equipment reliability, failures in IT systems, human errors, etc. As well, a number of risks are more a result of the management decisions (Simchi-Levi, 2004). In general, the supply chain risks arise from the interaction between supply chain members that two of them are mentioned:

- Risks of suppliers: including reliability, availability of materials, procurement time, material delivery issues etc.

- Risks of consumers: include the variable demand, production based on order etc.

Among the main reasons causing this risk in the supply chain can be a lack of sufficient cooperation between supply chain members. In contrast to internal supply chain risks, external risks existing arising from interactions with the external environment of chain including external events, weather conditions, legislation, natural disasters, war, etc. The most important feature of this type of risk is that it's out of the control of management, so managers do not have the ability to change the risks (Waters, 2007). Their intrinsic and extensive properties of supply chains make them vulnerable to risks. So a small event in one part of the chain can cause different results for the rest of the chain. In general it can be said that external risks are beyond the control of management of the organization, while internal risks can be controlled (Waters, 2007). 


\subsection{Risk management processes}

The first step in managing the risks of the supply chain is creating the risk strategy which is developed to reduce and balance operational risk of chain. Risk management in the supply chain is difficult and its causes can be various modes and forms of risks and differences in the planning horizon of managers and the organization (Rushton \& Walker, 2007). Therefore, supply chain risk strategy should be integrated in all parts of the organization and yet comprehensible for all management levels of the organization. In addition, the organization must continuously examine changes in the environment that need correction and update in supply chain risk strategy. When an organization has a risk strategy, it is able to evaluate all risks in the chain and after the assessment risks can be managed according to supply chain risk management strategy (Swaminathan, 2007).

According to the items mentioned, it can be concluded that all risks in the supply chain are of particular importance and their management is a crucial issue accordingly. In addition, to the extent that outsourcing strategies in an organization grows, growth of potential risks is also not unexpected (Harland et al., 2003).

Risk assessment is one of the pillars of risk management and objectives to measure risk based on various factors such as the impact and likelihood of occurrence and as the results of this phase are more accurate, it can be said that the risk management process is carried out with a higher degree of certainty. Rating risks, is the key to this process and makes determining the priority of each risk against other risks available so decision makers can make plans about the resources available to deal with any risk (Ghosh \& Jintanapakanont, 2004).

In Table 1, the most important researches in the field of supply chain risk and the way to deal with them are presented. According to Table 1, studies that include risk assessment have mainly used two indices (the impact) and (probability of occurrence) of risk in terms of probability-effect matrix. Some of the researchers have emphasized on unreliability of this process (Chapman \& Ward, 2003). Including problems using probability - effect matrix is that a risk with low probability and important effect might be ignored. Also, the risks that are likely to have high probability and no significant effect are deemed equivalent with risks having low probability and significant impact (Pipattanapiwong, 2004).

Some other risk assessment methods such as FMEA are used in other researches that the value of risk is calculated by multiplying three indexes, intensity, discovery rate and the probability of risk occurrence. However, there are weaknesses and bugs mentioned in this method. However, in order to evaluate and rank the risks in the research that has been done in other areas apart from the supply chain, Other parameters such as (the organization's ability to respond to risk) (McDermott et al., 1996) (uncertainty in estimation) (Klein \& Cork, 1998), probability and the possible impact on time and cost and quality of the projects have also been proposed in the ranking of risks (Baccarini \& Archer, 2001).

Supplementary measures of manageability and risk occurrence proximity (Pertmaster Software, 2002) and socioeconomic effects and environmental impact has also been used (Xu \& Liu, 2009). In cases where a substantial set of variables involved and there is the need to prioritize decision-making units based on their relative importance, utilization of various people ideas associated with the use of group decision making techniques and multiple attribute tools for ranking and making better decisions can be helpful (Pomerol \& Romero, 2000). 
Table 1

The most important researches in the field of supply chain risk

\begin{tabular}{|c|c|c|c|c|}
\hline Study & Approach & Type of risk & technique & Studied field \\
\hline Mangla et al., 2015 & Field study & Green supply chain & fuzzy AHP & Risk management \\
\hline Xia \& Chen, 2011 & Modelling & Aspects of the supply chain & ANP & Risk management \\
\hline Venkatesh, 2015 & Modelling & Retailers & $\begin{array}{l}\text { Interpretation structural } \\
\text { model }\end{array}$ & Risk analysis \\
\hline Giannakis, et al., 2016 & Conceptual & Sustainable supply chain & relational & Risk management \\
\hline Guneri et al., 2015 & Modelling & Relational & fuzzy AHP & Risk evaluation \\
\hline Kim \& Park, 2014 & Field study & Financial & Risk reduction strategies & Risk evaluation \\
\hline Badea et al., 2014 & Modelling & $\begin{array}{l}\text { Supply, production, distribution, } \\
\text { services and information technology }\end{array}$ & AHP & $\begin{array}{l}\text { Identification and risk } \\
\text { assessment }\end{array}$ \\
\hline Markmann et al., 2013 & Conceptual & Wholesalers area & $\begin{array}{l}\text { Probability- effect matrix, } \\
\text { Delphi method }\end{array}$ & $\begin{array}{l}\text { Identification and risk } \\
\text { assessment }\end{array}$ \\
\hline Dekker et al., 2013 & Conceptual & Supply, production and sale & Delphi method & $\begin{array}{l}\text { Identification and risk } \\
\text { control }\end{array}$ \\
\hline Wagner \& Neshat, 2010 & Modelling & Supply, demand & Graph theories & Risk evaluation \\
\hline Tuncel \& Alpan, 2010 & Simulation & Suppliers, manufacturers and customers & FMEA & $\begin{array}{l}\text { Identification and risk } \\
\text { assessment }\end{array}$ \\
\hline Sabio et al., 2010 & Modelling & Financial & $\begin{array}{l}\text { Mixed-integer linear } \\
\text { programming }\end{array}$ & Risk management \\
\hline Ravindran et al., 2010 & Modelling & Supply and failure & Optimization and AHP & Risk management \\
\hline Ellis et al., 2010 & Field study & Supply & $\begin{array}{l}\text { Interpretation structural } \\
\text { model }\end{array}$ & Risk evaluation \\
\hline Jia \& Rutherford, 2010 & Conceptual & Relational & modelling & Risk management \\
\hline Tang \& Musa, 2011 & Literature review & - & - & - \\
\hline Olson \& Wu, 2010 & Literature review & - & - & - \\
\hline Thun \& Hoenig, 2011 & Field study & The structure of the chain & Probability- effect matrix & $\begin{array}{l}\text { Identification and risk } \\
\text { assessment }\end{array}$ \\
\hline Tornow et al., 2009 & Case study & Supply & $\begin{array}{l}\text { Assessment of supply and } \\
\text { demand }\end{array}$ & $\begin{array}{l}\text { Identification and } \\
\text { assessment }\end{array}$ \\
\hline Oke \& Gopalakrishnan, 2009 & Case study & Supply and demand & Risk reduction strategies & Risk identification \\
\hline Braunscheidel \& Suresh, 2009 & Conceptual & Failure risk & $\begin{array}{l}\text { Study the effect of } \\
\text { fragility }\end{array}$ & Risk management \\
\hline Schoenherr, et al., 2008 & Case study & $\begin{array}{l}\text { Supply, demand, logistics, natural } \\
\text { disasters, etc. }\end{array}$ & AHP & Risk evaluation \\
\hline Tang \& Tomlin, 2008 & Modelling & Supply, demand and process & flexibility & Risk management \\
\hline Kull \& Closs, 2008 & Simulation & Supply & $\begin{array}{l}\text { Check the effect of the } \\
\text { increase in inventories }\end{array}$ & Risk evaluation \\
\hline Levary, 2008 & Case study & $\begin{array}{l}\text { Supply, natural disasters, related to } \\
\text { human and transport }\end{array}$ & AHP & Risk management \\
\hline Craighead et al., 2007 & Conceptual & Risk of the failure & relational & Risk management \\
\hline Ritchie \& Brindley, 2007 & Conceptual & Aspects of the supply chain & $\begin{array}{l}\text { Integrating risk and } \\
\text { performance }\end{array}$ & Risk management \\
\hline Tang, 2006 & Literature review & - & - & - \\
\hline Faisal et al., 2006 & Conceptual & Relational & $\begin{array}{l}\text { Interpretation structural } \\
\text { model }\end{array}$ & Risk management \\
\hline Kleindorfer \& Saad, 2005 & Conceptual & Economic failures and terrorism & modelling & Risk management \\
\hline Juttner, 2005 & Conceptual & Supply, demand and environmental & modelling & $\begin{array}{l}\text { Identification and risk } \\
\text { assessment }\end{array}$ \\
\hline Cavinato, 2004 & Conceptual & - & - & Risk identification \\
\hline Norrman \& Jansson, 2004 & Case study & - & - & $\begin{array}{l}\text { Identification and risk } \\
\text { assessment }\end{array}$ \\
\hline Chopra \& Sodhi, 2004 & Conceptual & Failures, delays, forecasting, & - & Risk management \\
\hline Zsidisin, 2003a & Case study & Supply & - & $\begin{array}{l}\text { Identification and } \\
\text { grouping }\end{array}$ \\
\hline Zsidisin, 2003b & Conceptual & Supply & modelling & Risk identification \\
\hline Ritchie \& Brindley, 2000 & Conceptual & - & - & $\begin{array}{l}\text { Risk management, small } \\
\text { and large organizations }\end{array}$ \\
\hline Applequist et al., 2000 & Modelling & Financial & $\begin{array}{l}\text { Random contractual } \\
\text { planning }\end{array}$ & Risk management \\
\hline
\end{tabular}




\subsection{Conceptual framework of the paper}

The framework considered in this paper is a process combined of ANP (based on proposed algorithm in (Khademi, et al., 2012) and ELECTRE multi-criteria decision making methods. The reasons of selecting combined ELECTRE-ANP method is as follows:

1. ANP weight calculation method is more accurate compared to direct method and it is possible to determine the compatibility between the given weights. Using this method also measures the relationship between the criteria involved in weight calculation.

2. Due to the large number of criteria and also the probability to increase (risk factors) depending on the industry, working with analytic network process (ANP) will increase paired comparisons leading to lower accuracy in calculations. So after weight calculation of criteria using ANP, ELECTRE method is used to detect and remove the less attractive alternatives and select more effective method because in this method all the alternatives are evaluated using non-ranking calculations and ineffective alternatives are eliminated doing so.

3. Since the identified risk factors in this paper are considered as the selection criteria, the alternatives having the least risk will be selected compared to others. So the ELECTRE method is utilized to select the best method.

\section{Research methodology}

This paper is practical-developmental in terms of the objective and it is descriptive- analytical in terms of data gathering and analysis. Risks of the supply chain are used as evaluation criteria and selecting the best strategy of the company in this paper in order to outsource some parts of the manufacturing process so that the company is able to improve its manufacturing process. For this purpose, two important decisions making methods are utilized and the evaluation process of the alternatives are briefly explained:

Step 1: The objectives determination and the criteria assessment: at this stage, the criteria evaluation is performed toward to the objective and the importance of the criteria $\left(W_{i}\right)$ is determined using the geometric mean method.

Step 2: Showing the relationship between the criteria: the relationship between the criteria and their dependence to each other is shown in the matrix form of $B_{N \times N}=\left[\begin{array}{ccc}b_{11} & \cdots & b_{1 N} \\ \vdots & \ddots & \vdots \\ b_{N 1} & \cdots & b_{N N}\end{array}\right]$ in this step. Then it is changed to a matrix with no scale using percentage method and it is multiplied to the weights of criteria $\left(W_{i}\right)$ to obtain final weights $\left(W_{C}\right)$.

Step 3: Creating decision making matrix of $D_{M \times N}=\left[\begin{array}{ccc}d_{11} & \cdots & d_{1 N} \\ \vdots & \ddots & \vdots \\ d_{M 1} & \cdots & d\end{array}\right]$ with each row assigned to an alternative and each column assigned to a specific criterion and each component of $d_{i j}$ shows the value of $i$ th alternative compared to $j$ th one. So the decision matrix consists of $\mathrm{M}$ alternative and $\mathrm{N}$ criteria. Step 4: Normalizing the decision making matrix of D using soft Euclidean method.

Step 5: Calculation of weighted matrix with no scales using $V=W_{c} \times R$ relation.

Step 6: Specifying a coordinated and uncoordinated set for each pair of $I, K=1,2, \ldots, m ; I \neq K$ alternatives. The set of existing index is divided into $\left(S_{K I}\right)$ coordinated distinct subset and uncoordinated ( $\left.D_{K I}\right)$ subset. The coordinated subset of $S_{K I}=\left\{j \mid r_{K j} \geq r_{I j}\right\}$ consists of $A_{k}, A_{I}$ alternatives and will include all indexes that $A_{K}$ is preferred to $A_{I}$ for them (i.e. $r_{i j}$ is assumed with increasing utility) and on the contrary, uncoordinated collection of series of $D_{K I}=\left\{j \mid r_{K j}<r_{I j}\right\}=J-S_{K I}$ is a set of indexes that for them $r_{i j}$ is assumed with decreasing utility. 
Step 7: Calculation of coordination and incoordination matrices: The possible value from coordination set of $\left(S_{K I}\right)$ is measured using the existing weights of coordinated indexes in the set. It means that each element (a measure of coordination) from the coordination matrix of $I_{K I}=\sum_{C_{j} \in S_{K I}} W_{C_{i}}$ is equal with the sum of weights of ( $\left.S_{K I}\right)$ indexes which also means that each element (a measure of coordination) from the coordination matrix of $\mathbf{I}$ is equal with the sum of weights of $\left(W_{C}\right)$ indexes that forms $\left(S_{K I}\right)$ set.

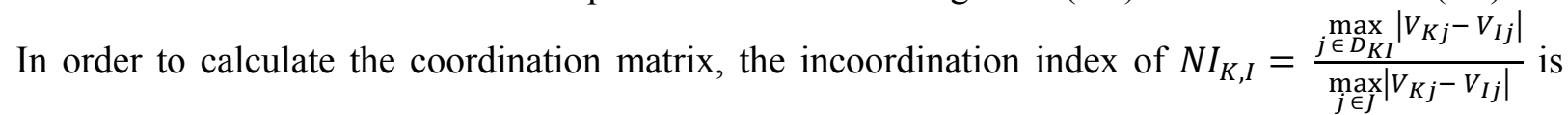
calculated using the elements of V matrix (weighted values) for uncoordinated set of $D_{K I}$.

Step 8: Determination of effective coordinated matrix and effective uncoordinated matrix: the values of $I_{K I}$ from the coordination matrix must be measured towards a threshold value to better judge the preferred chance of $A_{k}$ to $A_{I}$. The minimum threshold value of $\bar{I}=\sum_{K=1}^{m} \sum_{I=1}^{m} I_{K I} / m(m-1)$ can be calculated. A Boolean matrix of $\mathrm{F}=\left\{\begin{array}{ll}f_{K I}=1 & \stackrel{\text { if }}{\rightarrow} I_{K I} \geq \bar{I} \\ f_{K I}=0 & \text { if } \rightarrow I_{K I} \leq \bar{I}\end{array}\right.$ (with elements of zero and one) is formed. Then each unit element in $\mathbf{F}$ matrix (the effective coordinated matrix) represents an effective alternative which is dominant over the other. But in order to calculate the effective uncoordinated matrix, the elements of uncoordinated matrix of $\overline{N I}=\sum_{K=1}^{m} \sum_{I=1}^{m} N I_{K I} / m(m-1)$ must be measured toward a threshold value.. Then a Boolean matrix of $\mathrm{G}=\left\{\begin{array}{l}g_{K I}=1 \stackrel{\text { if }}{\rightarrow} N I_{K I} \leq \overline{N I} \\ g_{K I}=1 \stackrel{\text { if }}{\rightarrow} N I_{K I}>\overline{N I}\end{array}\right.$ (known as uncoordinated effective matrix) is formed and unit elements in this matrix show the relations among the alternatives. Step 9: Specification of the general and effective matrix and removing the less attractive alternatives: common elements of $h_{K I}=f_{K I} \cdot g_{K I}$ form a general $\mathrm{H}$ matrix from $\mathrm{F}$ and $\mathrm{G}$ matrices to make decisions in the following way:

The general $\mathrm{H}$ matrix represents the relative importance of alternatives which means that $A_{K}$ is preferred to $A_{I}$ both in terms of coordination and incoordination. But $A_{K}$ may still be dominated by other alternatives. Therefore, $A_{K}$ is an effective alternative using ELECTRE method if $\left\{\begin{array}{l}h_{K I}=1 \stackrel{\text { for at least one } I}{\longrightarrow} K \neq I \\ h_{K I}=0 \stackrel{\text { for all } I}{\longrightarrow} K \neq I\end{array}\right.$. The existence of these two conditions simultaneously may be rare. However effective alternatives can be realized easily using $\mathrm{H}$ matrix in a way that each column of $\mathrm{H}$ matrix having at least one unit element can be eliminated because that column is dominated by a row or some rows.

\section{Case study}

A company which manufactures medical equipment that seeks to select the most appropriate strategy to improve its product lines is considered as a case study in this paper. One of the key strategies of this company is outsourcing and making decisions about finding sources from outside the organization. The company faces four alternatives to optimize its production process which should select the best strategy according to the efficiency and effectiveness of each of the alternatives in increasing profitability and reducing probable risks. External suppliers play an important role in improving the manufacturing process of the company and a bulk of the components and parts used in the production of the final products (operating room vital signs monitors) is provided by the suppliers which creates competitive advantage for the company's products in domestic markets and abroad. The placement of production lines inside or outside the country is not the matter to be investigated in this paper, but the problem is that which geographical area outside the organization is suitable for these lines and how much of the entire production process must be done there. Finding the resources of parts and raw materials needed by the company is done by a supplier abroad but the company has decided to check other alternatives in order to reduce the costs and improve the quality and innovation in products as well as profitability. The suggested process in this paper helps the manufacturing organizations to have more discretion in 
selecting external alternatives to outsource some parts of the production process. In continuation of the review and analysis of the options facing the company are paid. Studying and analysis of alternatives facing the company is presented below.

1. Procurement of parts and raw materials from Singapore, and final product assembly in Tehran: By selecting this option parts and raw materials are procured from a supplier in Singapore and then transferred to Tehran and the final assembly is done in the company. Selecting this alternative involves advantages for the company including increased control over the assembly process and improving the quality of products in accordance with considered standards of manufacturer.

2. Procurement of completed equipment from Malaysia: Finding the resources for parts and raw materials has been mainly done this way. It means that a large part of the various stages of the manufacturing process has been done in the company contracted in Malaysia and selecting this alternative means the continuation of the company's present situation. On the other hand, continue to the current trend does not mean that the right to participate in other options is limited. Selecting this alternative, completed equipment are transferred from Malaysia to the company in Tehran using air transportation and then the final product manufacturing process is performed.

3. Procurement of completed equipment from Germany: Selecting this alternative not only the supplier source is transferred to another country but also another continent and this change of source may make the supply chain more complicated. As an instance, transportation to company in destination is a combination of aviation, marine and motor transportation because the ordered equipment is not directly transferred to Iran because of political reasons. But first, it is transferred to one independent country from the Persian Gulf countries and then it is transferred to Iran with the help of intermediaries and this causes change in the supply chain.

4. Procurement of parts and raw materials from Germany and final assembly in Malaysia through investment and joint venture with a German company: This includes investment in medical equipment production Installation in Malaysia done through the investment of a German company. Selecting this alternative increases the complication of supply chain that in the meantime, increasing the number of elements in chain and delays of transportation can be mentioned. The benefits of this strategy include providing qualified raw materials from Germany and final assembly performed by cheap labor in Malaysia's and then the final product transportation to Tehran through airlines. It should be noted that with respect to the joint investment with German counterpart, both companies in proportion to the share of investment, will benefit the profits.

Supply chain risk assessment framework is shown in Figure 1. In this diagram, the risk factors are considered as the criteria for selecting the best alternative among four considered ones. Much research has been done to identify the causes of supply chain risks. But noteworthy in this study is taking into account the relationships and mutual influences of risk factors in supply chain as the selection criteria. Now the 17 risk factors identified in this study are explained. In Figure 1, the objectives of Level 1 include features related to product sourcing, partners and the environment that the two products and partners have been divided into a number of sub-objectives. In relation to the target product, two subobjectives of quality and cost have been proposed that their related risk factors are as follows:

- The product quality (product failure rate): Suppliers must be able to meet the minimum standards of the final products to minimize the failure rate.

- Execution of systemic standard (ISO 13485): Represents the minimum level of acceptable quality for the production of medical equipment.

- Product cost: includes the price of products that the organization pays to its suppliers. 
- Competitors cost: the assessment of the purchasing cost of the organization compared to competing companies. Or in other words, the cost that the rival organization pays to the supplier to buy a similar product.

In conjunction with partners objectives, two sub objectives of services and management capabilities are of the utmost importance that the identified risk factors related to these sub-objectives re as follows:

- Demand risk: measures the likelihood and extent of fluctuations in product demand.

- Commitment risk of suppliers: The precision and commitment of suppliers for fulfilling the company orders from various aspects such as evaluation of quantitative and qualitative levels.

- Logistics risks: include uncertainty regarding the organizational aspects of logistics such as scheduling routes, selecting the harbor and transportation, completion of administrative law and what, how, at what time should be transferred.

- On time delivery: assesses the precision of a supplier in relation to responsiveness and flexibility of the transportation.

- Completing orders risk: the possibility of completion of the ordered products in terms of quality and quantity at the designated time will be assessed.

- Supplier's risk: the risk of supplier's bankruptcy or leaving the relevant business is evaluated.

- Overseas risk: the probability of disorders in the management of the external relations is measured. For example, due to political and cultural factors or time and place barriers as well as ethnic and linguistic differences between the countries, management of external relations is difficult.

- Supplier management: the way to manage the resources of first place suppliers or immediate suppliers is evaluated. The first place suppliers must have the necessary reliability. Because it is possible that first place suppliers will not be able to complete orders for various reasons, including lack of access to first-class raw and acceptable enough materials. As a result, the suppliers of next places will provide orders of first place suppliers. So, how to manage suppliers is very important.

As it is shown in Fig.1,

- Choosing the wrong partner risk: represents the probability of selecting partners with the possibility of poor performance and lacking sufficient performance in relation to the business. In a way that the selected partner does not have the ability for providing appropriate services to the client or an inappropriate supplier is selected to purchase materials and equipment.

- Engineering and innovation: shows the capabilities of suppliers in product innovation and appropriate design.

As shown in Fig. 1, the third main objective of the three participant ones is the environmental characteristics that the related identified risk factors are as follows:

$\checkmark$ Transportation risk: studies the possibility of problems in the transportation facilities that play an important role in the physical relocation of parts and equipment. These problems can include existing infrastructure in the host country, the capacity of harbors, cargo handling equipment, human resources and so on.

$\checkmark$ Incidents and natural disasters: the occurrence probability of incidents that may disrupt the supply chain, such as floods, storms, etc. are examined.

$\checkmark$ Board of directors' risk: including issues such as instability in political decisions, organizational strikes or cumbersome governmental rules that does not allow administrators to control the status properly. 


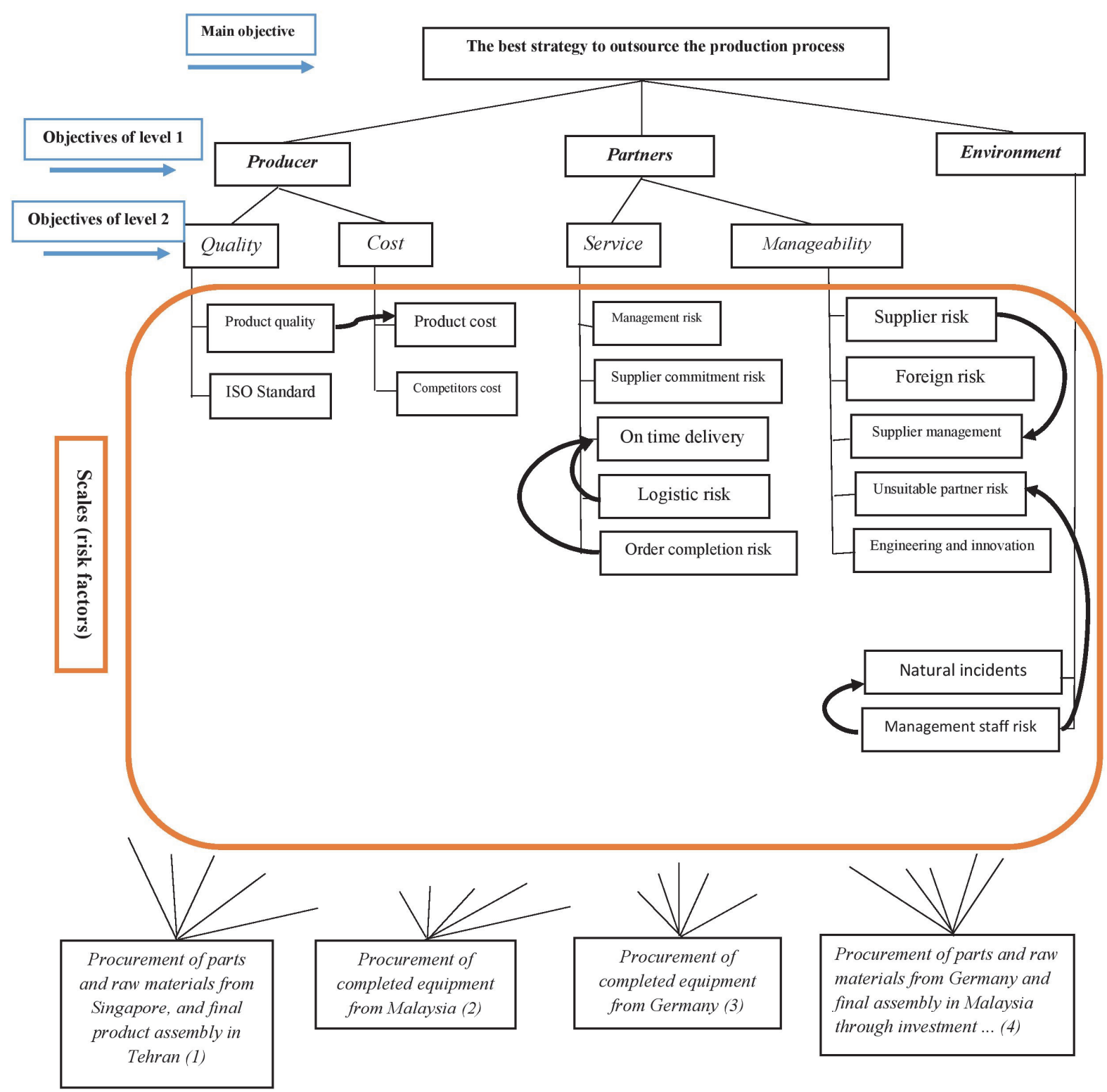

Fig. 1. The hierarchy of selecting for the best strategy the supply chain risk

As can be seen in Fig. 1, the influence of some standards and their interaction are shown. Then, using the proposed process, the alternatives considered by the company are assessed and prioritized. It should be noted that the oral judgments are used in doing comparisons in a way that if $i$ th element is compared to $j$ th element, it is said the importance of $i$ to $j$ is one of the following states that are changed into quantities from 1 to 9 . These judgments are proposed by Saati(1980). The weights of factors in each 
matrix are calculated and after making sure of the incompatibility rate of matrix in the range of acceptable less than 0.1, The fig. is used as the weights of factors compared in the matrix. After final calculations weights of criteria $\left(W_{i}\right)$ toward the main objective are obtained according to the Table 2 .

\section{Table 2}

The general weights of criteria (risk factors) toward the main objective, obtained from step 1

\begin{tabular}{cccc}
\hline Risk factor & $\boldsymbol{W}_{\boldsymbol{i}}$ & Risk factor & $\boldsymbol{W}_{\boldsymbol{i}}$ \\
\hline Product cost & 0.256 & Management staff risk & 0.022 \\
Product quality & 0.246 & Unsuitable partner choice risk & 0.021 \\
Order completion risk & 0.065 & Foreign risk & 0.021 \\
Transportation risk & 0.063 & Supplier risk & 0.020 \\
ISO 13485 & 0.062 & Demand risk & 0.010 \\
Competitors cost & 0.051 & Supplier management & 0.008 \\
Supplier commitment risk & 0.051 & Natural incidents and disasters & 0.008 \\
On time delivery & 0.051 & Engineering and innovation & 0.002 \\
Logistic risk & 0.043 & The sum of weights & 1.00 \\
\hline
\end{tabular}

Considering that the total incompatibility rate is less than $(0,1)$, so these paired comparisons are accepted. Now, according to step 2, the matrix of inter criteria relations (identified risk factors) is formed. Matrix numbers are based on the opinions of managers and experts in the purchase and supply of materials entered carefully and not based on judgments. After the formation of the matrix B it is normalized in percent and multiplied to the weight vector toward the objective $\left(W_{i}\right)$ in order to obtain the final criteria $\left(W_{c}\right)$ based on Table 3 .

Table 3

Final weights of identified risk factors

\begin{tabular}{cccc}
\hline Risk factor & $\boldsymbol{W}_{\boldsymbol{C}}$ & Risk factor & $\boldsymbol{W}_{\boldsymbol{C}}$ \\
\hline Product cost & 0.142 & Management staff risk & 0.012 \\
Product quality & 0.36 & Unsuitable partner choice risk & 0.021 \\
Order completion risk & 0.082 & Foreign risk & 0.025 \\
Transportation risk & 0.063 & Supplier risk & 0.02 \\
ISO 13485 & 0.063 & Demand risk & 0.005 \\
competitor cost & 0.051 & Supplier management & 0.008 \\
Supplier commitment risk & 0.025 & Natural incidents and disasters & 0.008 \\
On time delivery & 0.06 & Engineering and innovation & 0.001 \\
Logistic risk & 0.052 & The sum of weights & 0.998 \\
\hline
\end{tabular}

After the calculation of the final weights of the criteria $\left(W_{c}\right)$, ELECTRE method is used in order to remove non-effective alternatives and choose the most effective option among 4 alternatives available. Therefore the decision matrix of $\mathrm{D}$ is formed for the 4 alternatives considered and 17 identified risk factor as presented in Table 4.

Table 4

The decision matrix of $\mathrm{D}$ for the 4 alternatives considered and 17 identified risk factor

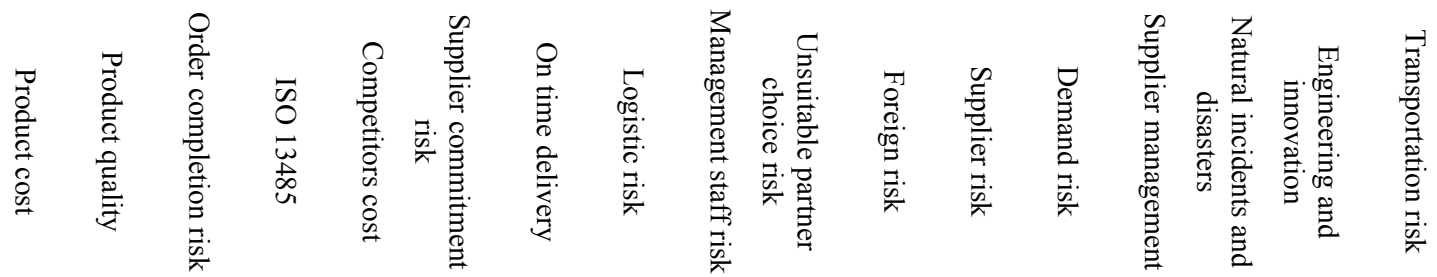

\begin{tabular}{llllllllllllllllll}
\hline$(1)$ & 0.04 & 0.03 & 0.09 & 0.06 & 0.02 & 0.02 & 0.01 & 0.06 & 0.05 & 0.07 & 0.03 & 0.01 & 0.07 & 0.01 & 0.04 & 0.03 & 0.07 \\
$(2)$ & 0.02 & 0.02 & 0.02 & 0.01 & 0.05 & 0.08 & 0.03 & 0.02 & 0.01 & 0.06 & 0.06 & 0.03 & 0.07 & 0.03 & 0.01 & 0.05 & 0.03 \\
$(3)$ & 0.01 & 0.05 & 0.03 & 0.05 & 0.08 & 0.02 & 0.08 & 0.01 & 0.03 & 0.07 & 0.05 & 0.02 & 0.02 & 0.01 & 0.02 & 0.01 & 0.01 \\
$(4)$ & 0.02 & 0.03 & 0.06 & 0.03 & 0.01 & 0.08 & 0.02 & 0.08 & 0.02 & 0.05 & 0.02 & 0.01 & 0.01 & 0.02 & 0.03 & 0.06 & 0.02 \\
\hline
\end{tabular}


It should be noted that the matrix of numbers represents the possibility of risk due to past experiences with regard to the selected alternative and as the risk occurrence probability related to an alternative is less, that alternative is considered as a priority by corporate managers of the company. The numbers entered in D decision matrix has been set based on previous purchases from suppliers and by the opinions of company experts. Matrix D is normalized according to steps 4 and 5 and then multiply it into the weights obtained for criteria from the $\left(W_{c}\right)$ matrix in order to have the weighted matrix with no scales. After the formation of $\mathrm{V}$ weighted matrix with no scales, the coordination set of $S_{K J}$ and the incoordination set of $D_{K J}$ are determined.

$$
I=\left[\begin{array}{cccc}
- & 0.776 & 0.77 & 0.84 \\
0.234 & - & 0.713 & 0.708 \\
0.226 & 0.279 & - & 0.205 \\
0.156 & 0.288 & 0.791 & -
\end{array}\right] \quad N I=\left[\begin{array}{cccc}
- & 0.318 & 0.01 & 0.244 \\
1 & - & 0.055 & 0.782 \\
1 & 1 & - & 0.205 \\
1 & 1 & 0.048 & -
\end{array}\right]
$$

The determination of coordinated effective matrix and effective matrix are based on $I=$ $\sum_{K=1}^{4} \sum_{I=1}^{4} I_{K J} / 12=\frac{5.976}{12}=0.498$ and $N I=\sum_{K=1}^{4} \sum_{I=1}^{4} N I_{K J} / 12=\frac{7.457}{12}=0.621$. The general matrix of $H=\left[\begin{array}{cccc}- & 1 & 1 & 1 \\ 0 & - & 1 & 0 \\ 0 & 0 & - & 0 \\ 0 & 0 & 1 & -\end{array}\right]$ indicatesType equation here. the relative priority of alternatives. Each column of this matrix having at least one unit element can be eliminated because that column is dominated by a row or some rows. So the first alternative is the most effective one and then the second and forth alternatives are considered as less attractive alternatives and finally the third alternative is the least attractive one.

\section{The SIMANP metaheuristic method:}

SIMP method involves the following steps; the first five steps are similar to Sa'ati's ANP method:

\section{Creating the model and changing the problem / issue to a network structure}

Model creation includes the following steps:

- Problem and objective definition

- Determination of criteria and decision making alternatives.

- Drawing a network structure in which the nodes are considered as clusters.

- Identifying the interdependencies of elements in a cluster with the arrow on the edges of the cluster and interdependencies with rings within the clusters.

\section{a. Compare binary matrix formation and determination of the priority vectors}

The paired comparisons are performed based on subjective analysis of the elements of a cluster in terms of related elements that are from the same cluster or other clusters and these comparisons are iterated for all clusters. These comparisons will initially be in the form of qualitative Likert statements and then can be quantified as a numerical scale of 1 to 9 . The pairwise comparison matrices are formed then and relative weights of elements are measured such as the AHP method.

\section{b. Calculating the size of the inconsistency of pairwise comparison matrices}

In this step, the error due to the inconsistency of pairwise comparison matrix is calculated. This error is calculated such as the AHP method. 
The value of inconsistency criteria is calculated using $C \cdot R=\frac{C . I}{R . I}$. Individual judgments are done through $C . I=\frac{\lambda_{\max }-n}{n-1}$ and group judgments are done using $C . I=\frac{\lambda_{\max }}{n}$.If matrix inconsistency index is smaller than (0.1), the judgment is acceptable; otherwise it should be revised.

\section{c. Imbalanced super matrix formation}

The alternatives, criteria and sub-criteria are all brought in rows and columns in super matrix structure and relative weights obtained in pairwise comparison matrices are placed in this matrix and also if an element is related to itself the value of 1 is assigned to the imbalanced super matrix. The figure below shows the general structure of the super matrix. Jth element is of $i$ th cluster and $W_{i k}$ is the block matrix that represents the weight of the vector affected by the $i$ th component of the cluster associated with the $k$ th cluster.

If association between clusters exists, the pairwise comparison matrix of clusters is formed and the relative weight of clusters are obtained and entered into a matrix called the AHP matrix such as the cluster method.

\section{d. The formation of weighted super matrix}

At this stage the weighted super matrix is obtained by multiplying the non-weighted matrix values into cluster matrix and normalization of each column of non-weighted super matrix.

The differentiation of SIMANP method is clear in the later stages including:

\section{e. The calculation of weighed super matrix}

The elements in problem $\left(e_{i j}\right)$ are divided into two categories of sub criteria and alternatives. So if the number of sub criteria is equal to $\mathrm{n}\left(C_{1}, C_{2}, \ldots, C_{n}\right)$ and the number of alternatives are equal to $\mathrm{m}$ $\left(A_{1}, A_{2}, \ldots, A_{m}\right)$, the weighted super matrix is as follows:

Figure2, the weighted supper

matrix

$\dot{C} \quad\left[\begin{array}{ll}W_{c c} & A \\ W_{A C} & W_{C A}\end{array}\right]$

The weighed super matrix is composed of 4 following matrices:

1. $\left[W_{c c}\right]$ : The matrix of relative weights of sub criteria in terms of sub criteria.

2. $\left[W_{c A}\right]$ : The matrix of relative weights of sub criteria in terms of alternatives.

3. $\left[W_{A C}\right]$ : The matrix of relative weights of alternatives in terms of sub criteria.

4. $\left[W_{A A}\right]$ : The matrix of relative weights of alternatives in terms of alternatives.

In this step the values of $u_{l}=\sum_{j} W_{C_{l} C_{j}}+\sum_{j} W_{C_{l} A}$ are obtained as below. Simply, $\bar{u}=\left[\begin{array}{c}u_{1} \\ \vdots \\ u_{n}\end{array}\right]$ is equal to the sum of relative weights of $C_{l}$ criteria in terms of criteria and alternatives of weighted super matrix. After $u_{l}$ is obtained, $\bar{u}$ is formed and finally $\overline{u^{\prime}}=\left[\begin{array}{c}u_{1}^{\prime}=\frac{u_{1}}{u_{1}+\ldots+u_{n}} \\ \vdots \\ u_{n}^{\prime}=\frac{u_{n}}{u_{1}+\ldots+u_{n}}\end{array}\right]$ is obtained by normalizing $\bar{u}$.

\section{The calculation of $\bar{L}$}


$\bar{L}=\left[W_{A C}\right] \times \bar{u}^{\prime}$ Is obtained in this step.

\section{The calculation of $S_{l}$}

The values of $S_{l}=\sum_{j} W_{A_{l} A_{j}}+\sum_{j} W_{A_{j} A_{l}}$ are obtained from the related weight matrix of alternatives in terms of alternatives as follows:

$$
\left[W_{A A}\right]=\left[\begin{array}{ccc}
W_{A_{1} A_{1}} & \cdots & W_{A_{1} A_{m}} \\
\vdots & \ddots & \vdots \\
W_{m A_{1}} & \cdots & W_{A_{m} A_{m}}
\end{array}\right]
$$

$W_{A_{l} A_{j}}$ the relative weight of $A_{l}$ in terms of $A_{j}$.

$W_{A_{j} A_{l}}$ the relative weight of $A_{j}$ in terms of $A_{l}$.

Then $\bar{S}=\left[\begin{array}{c}S_{1} \\ \vdots \\ S_{m}\end{array}\right]$ is formed.

\section{The calculation of $\overline{\boldsymbol{N}}$}

$\bar{N}_{m \times 1}=\bar{L}_{m \times 1}+\bar{S}_{m \times 1}$ is obtained.

\section{The normalization of $\bar{N}$}

Now, normalizing $\bar{N}_{m \times 1}$ using percent method ${\overline{N^{\prime}}}_{m \times 1}$ is obtained which is the final relative weight of alternatives.

To assess the results of SIMANP, responses received from two proposed ANP_ELECTRE and SIMANP algorithm are compared and the results are shown in Table 6.

\section{Table 6}

Comparing the results of ANP-ELECTRE and SIMANP algorithm

\begin{tabular}{|c|c|c|c|}
\hline & ANP - ELECTRE & SIMANP & $G A P \times 10^{-4}$ \\
\hline The cost of product & 0.142 & 0.147 & 143 \\
\hline The quality of the product & 0.36 & 0.36 & 0 \\
\hline Order completion risk & 0.082 & 0.09 & 889 \\
\hline ISO 13485 & 0.063 & 0.058 & 862 \\
\hline Competitors costs & 0.062 & 0.062 & 0 \\
\hline Supplier commitment risk & 0.051 & 0.045 & 1333 \\
\hline On time delivery & 0.025 & 0.026 & 346 \\
\hline Logistics risk & 0.06 & 0.06 & 0 \\
\hline Board of directors risk & 0.052 & 0.052 & 0 \\
\hline Risk of choosing inappropriate partner & 0.012 & 0.015 & 2000 \\
\hline External risk & 0.021 & 0.03 & 3000 \\
\hline Supplier risk & 0.025 & 0.03 & 1667 \\
\hline Demand risk & 0.005 & 0.006 & 1667 \\
\hline Supplier management & 0.005 & 0.006 & 1667 \\
\hline Incidents and natural disasters & 0.008 & 0.008 & 0 \\
\hline Engineering and innovation & 0.008 & 0.006 & 3333 \\
\hline Transportation risk & 0.001 & 0.001 & 0 \\
\hline
\end{tabular}

\section{Conclusion}

Nowadays a number of industrial organizations provide part of their requirements by external suppliers or parts of the production lines are assigned to the out of the organization. In this context, each of the alternatives considered by the organizations, have the advantages and disadvantages regarding the evaluation criteria. In this study the risk factors contained in the company's supply chain are considered 
as criteria for selecting the most suitable alternatives to transfer part of the production process. Due to this, the existence of a flexible method for measuring the constraints of suppliers and requirements of organization is necessary to evaluate and decide on the most appropriate and most effective solution. According to calculations carried out in accordance with the process proposed in this paper and the available information about the possible risks of the company's supply chain, the most appropriate and most effective solution among the four available alternatives to transfer part of the production process outside the borders, is supplying parts and raw materials from Singapore, and do the final product assembly in Tehran. This alternative involves advantages for the manufacturer company including increased control over the assembly process and enhanced the quality of products in accordance with the manufacturer considered standards. The second strategy for the company is to select one of two alternatives of the second one or the fourth one. The second alternative is a continuation of the previous trend to by the competed equipment from Malaysia. With this option, all the equipment is transferred from Malaysia on a weekly basis with the use of air freight to participate in Tehran and then final product manufacturing process is performed. And selecting the third alternative means the procurement of parts and raw materials is done in Germany and final product assembly is performed in Malaysia through investment and joint venture with a German company (This includes investment in medical equipment production facility in Malaysia through a joint venture with a German company). The least attractive alternative is the third option, because it increases the probability of risks and on the other hand political reasons and economic sanctions of related industries, makes this alternative non effective. Also in order to allow faster calculations while obtaining optimal results, the expressed problem is solved by SIMANP meta-heuristic algorithm and the results were presented. According to the results of the comparison between the two proposed algorithms it can be expressed that using the ANP - ELECTER combined algorithm provides more appropriate and acceptable results. But involves higher computational complexity compared to meta-heuristic method introduced. While the use of meta-heuristic algorithm is very fast and does not require software computations. So when quick results are preferred to high accuracy, using this method is suggested. Because the study only examined the relationship between measures considering the obtained results it is suggested to the researchers to study the relationship between alternatives and criteria and their relations in addition to the study of the relation between criteria and provide more accurate results in future studies.

\section{References}

Applequist, G. E., Pekny, J. F., Reklaitis, G. V. (2000). Risk and uncertainty in managing chemical manufacturing supply chains. Computers and Chemical Engineering, 24 (9-10), 2211-2222. Asgarpour, M. J. (2008). Multiple criteria decision making (8rd ed.). Tehran: University of Tehran press.

Azadi, M., \& Saen, R. F. (2011). Developing an Output-Oriented Super Slacks-Based Measure Model with an Application to Third-Party Reverse Logistics Providers. Journal of Multi-Criteria Decision Analysis, 18(5-6), 267-277.

Baccarini, D., \& Archer, R. (2001). The risk ranking of projects: a methodology. International Journal of Project Management, 19 (3), 139-145.

Badea, A., Prostean, G., Goncalves, G., \& Allaoui, H. (2014). Assessing Risk Factors in Collaborative Supply Chain with the Analytic Hierarchy Process (AHP). Procedia - Social and Behavioral Sciences, $124,114-123$

Bayazidi, A., Oladi, B., \& Abbasi, N. (2012). Questionnaire data analysis usin, SPSS software (PASW) 18. Tehran: Mehregan Galam.

Braunscheidel, M. J., \& Suresh, N. C. (2009). The organizational antecedents of a firm's supply chain agility for risk mitigation and response. Journal of Operations Management, 27(2), 119-140.

Brindley, C. (2004). supply chain risk. England, ASHGATE. Cavinato, J. L. (2004). Supply chain logistics risks from the back room to the board room. International Journal of Physical Distribution \& Logistics Management, 34(5), 383-387.

Chapman, C. B., \& Ward, S. C. (2003). Project Risk Management: Processes, Techniques and Insights. UK: Chichester, John Wiley . 
Chopra, S., \& Sodhi. M. S. (2004). Managing risk to avoid supply-chain breakdown. MIT Sloan Management Review, 46(1), 53-61.

Craighead, C. W., Blackhurst, J., Rungtusanatham, M. J., \& Handfield, R. B. (2007). The severity of supply chain disruptions: Design characteristics and mitigation capabilities. Decision Sciences, 38(1), 131-156.

Dekker, H., Sakaguchi, J., \& Kawai, T. (2013). Beyond the contract: Managing risk in supply chain relations. Management Accounting Research, 24(2), 122-139.

Ellis, S. C., Henry, Raymond, M., \& Shockley, J. (2010). Buyer perceptions of supply disruption risk: A behavioral view and empirical assessment. Journal of Operations Management, 28(1), 34-46.

Faisal, M. N., Banwet, D. K., \& Shankar, R. (2006). Supply chain risk mitigation: modeling the enablers. Business Process Management Journal, 12(4), 535-552.

Ghosh, S., \& Jintanapakanont, J. (2004). Identifying and assessing the critical risk factors in an underground rail project in Thailand: a factor analysis approach. International Journal of Project Management, 22(8), 633-643.

Giannakis, M., \& Papadopoulos, T. (2016). Supply chain sustainability: a risk management approach. International Journal of Production Economics, 171, 455-470.

Guneri, A. F., Gul, M., \& Ozgurler, S. (2015). A fuzzy AHP methodology for selection of risk assessment methods in occupational safety. International Journal of Risk Assessment and Management, 18(3-4), 319-335.

Harland, C., Brenchley, R., \& Walker, H. (2003). Risk in supply networks. Journal of Purchasing and Supply Management, 9(2), 51-62.

Handfield, R., \& McCormack, K. P. (Eds.). (2007). Supply chain risk management: minimizing disruptions in global sourcing. CRC press.

Jia, F., \& Rutherford, C. (2010). Mitigation of supply chain relational risk caused by cultural differences between China and the West. International Journal of Logistics Management, 21(2), 251-270.

Juttner, U. (2005). Supply chain risk management: Understanding the business requirements from a practitioner perspective. The International Journal of Logistics Management, 16(1), 120-141.

Khademi, N., Mohaymany, A. S., Shahi, J., \& Zerguini, S. (2012). An algorithm for the analytic network process (ANP) structure design. Journal of Multi-Criteria Decision Analysis, 19(1-2), 33-55.

Kim, K. K., \& Park, K. S. (2014). Transferring and sharing exchange-rate risk in a risk-averse supply chain of a multinational firm. European Journal of Operational Research, 237(2), 634-648.

Klein, J. H., \& Cork, R. B. (1998). An approach to technical risk assessment. International Journal of Project Management, 16(6), 345-351.

Kleindorfer, P. R., \& Saad, G. H. (2005). Managing disruption risks in supply chains. Production and Operations Management, 14(1), 53-58.

Kull, T., \& Closs, D. (2008). The risk of second-tier supplier failures in serial supply chains: Implications for order policies and distributor autonomy. European Journal of Operational Research, 186(3), 11581174.

Levary, R. R. (2008). Using the analytic hierarchy process to rank foreign suppliers based on supply risks. Computers \& Industrial Engineering, 55(2), 535-542.

Mangla, S. K., Kumar, P., \& Barua, M. K. (2015). Prioritizing the responses to manage risks in green supply chain: An Indian plastic manufacturer perspective. Sustainable Production and Consumption, 1, 67-86.

Mangla, S. K., Kumar, P., \& Barua, M. K. (2015). Risk analysis in green supply chain using fuzzy AHP approach: a case study. Resources, Conservation and Recycling, 104, 375-390.

Markmann, C., Darkow, L. L., \& Gracht, H. V. D. (2013). A Delphi-based risk analysis — Identifying and assessing future challenges for supply chain security in a multi stakeholder environment. Technological Forecasting and Social Change, 80(9), 1815- 1833.

McDermott, R. E., Mikulak, R. J., \& Beauregard, M. R. (1996). The basics of FMEA. New York: Quality Resources. 
Norrman, A., \& Jansson, U. (2004). Ericsson's proactive supply chain risk management approach after a serious sub-supplier accident. International Journal of Physical Distribution \& Logistics Management, $34(5), 434-456$.

Oke, A., \& Gopalakrishnan, M. (2009). Managing disruptions in supply chains: A case study of a retail supply chain. International journal of Production Economics, 118(1), 168-174.

Olson, D. L., \& Wu, D. D. (2010). A review of enterprise risk management in supply chain. Kybernetes, 39(5), 694-706.

Pertmaster Software. (2002). Pertmaster Project Risk v7.5: Tutorial, manual and help. Available on: http://www.pertmaster.com. /

Pipattanapiwong, J. (2004). Development of multi-party risk and uncertainty management process for an infrastructure project (Doctoral dissertation), Kochi University of Technology, Japan.

Pomerol, J. C., \& Romero, S. B. (2000). Multi-criterion decision in management: Principles and practice. Netherlands: Kluwer Academic, Dordrecht.

Ravindran, A. R., Bilsel, R. U., Wadhwa, V., \& Yang, T. (2010). Risk adjusted multi criteria supplier selection models with applications. International Journal of Production Research, 48(2), 405-424.

Ritchie, B., \& Brindley, C. (2000). Disintermediation, disintegration and risk in the SME global supply chain. Management Decision, 38(8), 575-583.

Ritchie, B., \& Brindley, C. (2007). Supply chain risk management and performance A guiding framework for future development. International Journal of Operations \& Production Management, 27(3), 575583.

Rushton, A., \& Walker, S. (2007). (international Logistic and Supply chain outsourcing) : from local to global / - HD38.5.R867.

Saaty, T. L., \& Vargas, L. G. (2006). Decision making with the analytic network process: economic, political, social and technological applications with benefits, opportunities, costs and risks. New York: Springer.

Sabio, N., Gadalla, M., Guille'n-Gosa'lbez, G., \& Jime'nez, L. (2010). Strategic planning with risk control of hydrogen supply chains for vehicle use under uncertainty in operating costs: A case study of Spain. International journal of hydrogen energy, 35(3), 6836-6852.

Schoenherr, T., Tummala, V.M. R., \& Harrison, T. P. (2008). Assessing supply chain risks with the analytic hierarchy process: Providing decision support for the offshoring decision by a US manufacturing company. Journal of Purchasing \& Supply Management, 14(2), 100-111.

Simchi-Levi, D., Kaminsky, P., \& Simchi-Levi, E. (2004). Managing the supply chain: the definitive guide for the business professional. McGraw-Hill Companies.

Swaminathan, J.M., \& Tomlin, B. (2007). How to avoid the 6 risk management pitfalls. Supply Chain Management Review, 11(5), 34-42.

Tang, C. S. (2006). Perspectives in supply chain risk management. International Journal of Production Economics, 103(2), 451-488.

Tang, C., \& Tomlin, B. (2008). The power of flexibility for mitigating supply chain risks. International journal of Production Economics, 116(1), 12-27.

Tang, O., \& Musa, S. N. (2011). Identifying risk issues and research advancements in supply chain risk management. International journal of Production Economics, 133(1), 25-34.

Thun, J. H., \& Hoenig, D. (2011). An empirical analysis of supply chain risk management in the German automotive industry. Production Economics, 131(1), 242- 249.

Tornow, R., Osenau, D., Buchholz, P., Riemann, A., \& Wagner, M. (2009). Assessing the long term supply risks for mineral raw materials - a combined evaluation of past and future trends. Resources Policy, 34(4), 161-175.

Tuncel, G., \& Alpan, G. (2010). Risk assessment and management for supply chain networks: A case study. Computers in Industry, 61(3), 250-25.

Vanany, I., Zailani, S., \& Pujawan, N. (2009). Supply chain risk management: Literature review and future research. 16 International Journal of Information Systems and Supply Chain Management, 2(1), 1633. 
Venkatesh, V. G., Rathi, S., \& Patwa, S. (2015). Analysis on supply chain risks in Indian apparel retail chains and proposal of risk prioritization model using Interpretive structural modeling. Journal of Retailing and Consumer Services, 26, 153-167.

Wagner, S. M., \& Neshat, N. (2010). Assessing the vulnerability of supply chains using graph theory. International journal of Production Economics, 126(1), 121-129

Waters, D. (2011). Supply chain risk management: vulnerability and resilience in logistics. Kogan Page Publishers.

Xia, D., \& Chen, B. (2011). A comprehensive decision-making model for risk management of supply chain. Expert Systems with Applications, 38(5), 4957-4966.

Xu, L., \& Liu, G. (2009). The study of a method of regional environmental risk assessment. Journal of Environmental Assessment, 90(11), 3290-3296.

Zsidisin, G. A. (2003a). Managerial perceptions of supply risk. Journal of Supply Chain Management, 39(1), 14-25.

Zsidisin, G. A. (2003b). A grounded definition of supply risk. Journal of Purchasing \& Supply Management, 9(5-6), 217-22.

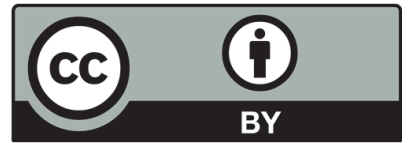

(C) 2016 by the authors; licensee Growing Science, Canada. This is an open access article distributed under the terms and conditions of the Creative Commons Attribution (CC-BY) license (http://creativecommons.org/licenses/by/4.0/). 